\title{
ICOM \\ Scientific research in news media: a case study of misrepresentation, sensationalism and harmful recommendations
}

\section{Georgia Dempster, Georgina Sutherland and Louise Keogh}

\begin{abstract}
Accurate news media reporting of scientific research is important as most people receive their health information from the media and inaccuracies in media reporting can have adverse health outcomes. We completed a quantitative and qualitative analysis of a journal article, the corresponding press release and the online news reporting of a scientific study. Four themes were identified in the press release that were directly translated to the news reports that contributed to inaccuracies: sensationalism, misrepresentation, clinical recommendations and subjectivity. The pressures on journalists, scientists and their institutions has led to a mutually beneficial relationship between these actors that can prioritise newsworthiness ahead of scientific integrity to the detriment of public health.
\end{abstract}

Keywords

DOI

Introduction
Health communication; Public engagement with science and technology; Science and media

https://doi.org/10.22323/2.21010206

Submitted: 17th December 2020

Accepted: 20th January 2022

Published: 7th March 2022

\section{Media and scientific research}

Clear, balanced and accurate representation of scientific research in news media is important. Media both shape and reflect public opinion [Caulfield et al., 2014]. The public receive a significant amount of their health information from the media [Caulfield et al., 2014; Phillips et al., 1991]. Those who receive their health information from the media are not limited to general audiences but include content experts such as healthcare professionals and policy makers [Geller, Bernhardt and Holtzman, 2002]. Media coverage of health issues can influence government policy [King, Schneer and White, 2017] and impact healthcare decision making [Johnson, 1998]. Health information in news media can have a greater impact on public health behaviour than government led and supported public health campaigns [Seale, 2003]. Whilst scientific research includes vast fields that 
encompass many disciplines of investigation in both in the natural (biology, chemistry, physics) and social world (sociology, anthropology, psychology), in this paper, we refer to 'scientific research' as a short-hand way of referring to lab-based and clinical research with clear translations and implications for human health.

Research in natural scientific fields is generally considered positivist. Positivist research, like that undertaken in the case that is described in this study, is viewed as researchers working from a paradigm in which objective truths about the world can be developed through rigorous adherence to the scientific method. Scientific research uses rigorous methods to ensure researcher objectivity and minimise bias [O'Connor and Joffe, 2014]. However, a subtle shift occurs when scientific research is written about in public domains such as mainstream news media [O'Connor and Joffe, 2014]. Given the goals of media communication, the overall complexity, phrasing, language, and the relatability of the science needs to be adapted for a mainstream audience. Researchers' goal of reporting high quality scientific research in media and the need for scientific research to be comprehensible and newsworthy presents competing priorities. As social science researchers, we view this under-investigated tension as important and worthy of study. Throughout this article we use a social constructivist perspective to investigate and explain the tensions that emerge when scientists communicate the outcomes of positivist science outside of the strict confines of academic publishing. We acknowledge the socially constructed nature of the journal article, the press release and news media reporting and aim to explore the processes, structures and activities that create these different modes of communication.

Since the 1990's there have been significant changes to news media environments that have impacted both on the way science is communicated to the public and the way consumers of news engage with, and receive information about science. Recent changes include that ownership of media organisations has become more concentrated and media has become more digitized with convergence across platforms [Erdal, 2019]. In contemporary society, the public engages with news across multiple platforms using both traditional and digital sources. In 2018, the Pew Research Centre reported that people in the U.S. are most likely to receive their news from television followed by news websites, radio, social media and print newspapers [Shearer, 2018]. In 2019, Ofcom reported that people in the United Kingdom (U.K.) are most likely to receive their news from television followed by internet sources, radio and then print newspapers [Ofcom, 2019]. In 2019, Reuters Institute for the Study of Journalism reported that Australians are most likely receive their news from online sources followed by television, print and social media [Newman et al., 2019]. Important to note is that the sources that people receive their news from are shifting with online content being of increasing importance, especially for younger audiences such as those aged 18-29. In the U.S., for example, most young people report consuming news via social media followed by news websites [Shearer, 2018].

In addition to the change in ways that society consume news, there has been a steady decline in employment of 'traditional' journalists globally. In Australia around a third of all print journalist positions were lost in the twenty years from 1996 to 2016 [O'Regan and Young, 2019]. In the U.S., newsroom employment dropped by $23 \%$ from 2008 to 2019 [Walker, 2021]. These job losses have coincided with a steady decline in the circulation, readership and advertising revenue of 
print newspapers [Barthel, 2017]. As in many other countries, Australia has also seen a steep decline in specialist science journalists, with general journalists now covering science-related news without necessarily having any science training [Watkins, 2019]. In addition, the speed of today's news production has resulted in the disappearance of scrutinised information and considered reflection [Le Masurier, 2015]. The pressure to produce real time news has resulted in greater inaccuracy [Hargreaves, 2003] and a dependence on press releases that are written by the public relations professionals employed by universities and research institutes [Lewis et al., 2008]. Even if journalists had the time to read journal articles, the majority of those articles remain behind journal paywalls [Butler, 2016]. Journalists are also under increasing pressure to generate 'click bait' and are therefore driven by headlines that include words such as "breakthrough". In combination with a lack of science training and time pressures this results in inaccuracies and sensationalist stories being published [Watkins, 2019]. Research has shown that inaccurate or exaggerated scientific reporting has, in part, been a result of the information in the press releases [Sumner et al., 2016].

Researchers have reported that the desire to create newsworthy stories about science led to a perverse situation where poorer quality research can garner more news coverage than robust research based on a strong priori hypothesis, as the poorer research is more likely to yield surprising and newsworthy results. For example, Selvaraj and colleagues investigated study designs of medical research published in news media and found that newspapers were less likely to cover randomised controlled trials than observational studies and therefore preferentially reported on medical research with weaker study designs [Selvaraj, Borkar and Prasad, 2014]. Another example of this is when the poorly designed and subsequently retracted and debunked study led by Andrew Wakefield and published in the Lancet that described an association between the measles/mumps/rubella (MMR) vaccine and autism was widely published in news media and resulted in a reduced vaccination rate of children for years following the publication of the article [Godlee, Smith and Marcovitch, 2011]. Research designed to quantify the effect of this paper has demonstrated that this one study alone has been a primary cause of childhood vaccine scepticism in the U.S. highlighting that media attention of inaccurate scientific research can undermine public trust in vaccines [Motta and Stecula, 2021]. This case of the MMR vaccine is an example of widespread and damaging news coverage from a poorly design scientific study. The consequences of communicating scientific research via media when it involves misinformation, like the MMR vaccine, can lead to public misunderstanding, distrust in science and harmful health behaviours [Kata, 2010].

Other researchers have highlighted, that unlike for scientists, for the media, communicating the limitations and risks of a study may be of a lower priority. Omission of limitations and risk has been reported in a number of studies, Caulfield and colleagues found that vitamin D when reported on in news media was linked to a variety of health conditions for which there is no definitive scientific evidence in addition to under reporting the risks associated with vitamin supplementation [Caulfield et al., 2014]. Cassels and colleagues analysed the representation of five specific drugs in Canadian newspapers with the main findings being that the majority of articles did not mention potential side effects or harms [Cassels et al., 2003]. Schwitzer summarised the work of independent health news reviewing organisation 'healthnewsreview.org' which evaluated 1,800 health 
news stories across many U.S. news organisations. Findings showed that $70 \%$ of health news articles were deemed unsatisfactory when assessed for attributes such as quantifying potential harms and benefits and reporting on costs [Schwitzer, 2013]. Researchers have theorised that the omission of limitations and risks in the reporting of scientific studies in news media is to increase their newsworthiness or conversely, as described by Mellor, reporting on attributes such as limitations is considered a non-news value [Mellor, 2015].

In addition to the omission of limitations and risks, writing techniques used in journal articles, press releases and news media to make scientific research more newsworthy include the use spin and positive framing. In the context of scientific research, spin has been described as communicating findings so that the benefits of an intervention seem stronger or more positive than they actually are [Haneef et al., 2015]. The motivations to use spin to increase newsworthiness when writing about scientific research in news media have been linked to scientists, public relations specialists and journalists. In an analysis of randomised controlled trials reported in news media, Yavchitz and colleagues reported that the key predictor of 'spin' in a press release was the use of 'spin' in the conclusion of the abstract of the journal article [Yavchitz et al., 2012]. Even before the journal article is published, researchers have found that spin can be present at the beginning of the research process from grant applications in addition to academic journal articles and consequentially any material that is based on these documents [Landhuis, 2016]. Others have argued that spin can be introduced in the press release. Sumner and colleagues found that exaggerations and warnings in news reports mirrored those in press releases [Sumner et al., 2016]. Others have found fault with the practice of journalists. Taylor and colleagues [Taylor et al., 2015] investigated the accuracy of news media coverage of a meta-analysis (a complex statistical method that combines results across multiple studies) investigating the link between pancreatic cancer and processed meat. The authors found that most news reports were derived from secondary sources such as the journal press release and that the quality of the news reports was dependent on the quality of the secondary sources from which the news reports were derived [Taylor et al., 2015].

Framing is another technique that, when a news article is produced, will highlight and downplay certain elements of a story to promote a specific predetermined understanding [Entman, 2007]. News frames, therefore, can exert power over readers' beliefs, attitudes and behaviours [Oliver, Raney and Bryant, 2019]. Furthermore, sense making theory suggests that readers consume news media portrayed in specific frames, as a short cut to understand complex topics [Scheufele and Lewenstein, 2005; Shih, Wijaya and Brossard, 2008]. Framing can therefore yield problematic representation and sense making interpretations of science if a study has been inaccurately portrayed for the purpose of newsworthiness for the benefit of media, scientists or both. Given that science needs to be both understandable and relatable to be newsworthy [Fuoco, 2021], it makes sense that there are shared motivations of scientists, public relations professionals and journalists that may result in techniques such as spin and framing to make scientific research more newsworthy. However, it also makes sense that, to garner interest in scientific research, research findings may be exaggerated and their implications inflated [Vinkers, Tijdink and Otte, 2015] via mechanisms such as spin and framing. 
The reasons that scientists increasingly prioritise public engagement are complex [Besley and Nisbet, 2013]. In addition to publishing in academic journal articles, there is an expectation that academics participate in public engagement [Glynn, 2016; Rawat and Meena, 2014]. Research from the U.K. has highlighted that the most important reasons for academics to engage with public audiences are to increase funding success by demonstrating research impact and to increase their institution's competitiveness [Watermeyer and Lewis, 2018]. The relationships that exist between scientists and the public can be understood using the theoretical models of science communication [Metcalfe, 2019]. Over time, there have been many theoretical models of communication proposed, each based on different assumptions and definitions of communication [Burns, $\mathrm{O}^{\prime}$ Connor and Stocklmayer, 2003]. The three main theoretical models of science communication described in academic literature include the deficit, dialogue and participation models [Metcalfe, 2019]. These three models underpin the communication strategies within two of the most commonly described paradigms of science communication. The deficit model belongs to the public understanding of science (PUS) paradigm and the dialogue and participation models belong to the public engagement with science and technology (PEST) paradigm [Schäfer, 2009]. The deficit model assumes that the public's lack of understanding of science leads to the public being sceptical about science [Sturgis and Allum, 2004] and that public doubts and uncertainty about science are a result of ignorance about science [Gross, 1994; Sturgis and Allum, 2004]. In contrast to the deficit model, the dialogue and participation models emphasise informing and communicating diverse views and critical reflections about scientific issues to public audiences [Kamenova, 2017]. A PUS paradigm can oversimplify information in an attempt to facilitate public understanding. In contrast, the PEST paradigm does not assume the public are deficient in knowledge and thus seeks to communicate critical reflections about science. Evolving from the PEST paradigm, medialisation is a theory that seeks to understand the mutually beneficial relationship between science and the media, specifically; scientists' awareness of the strategic benefits of direct media engagement and in turn, media's increased science coverage [Rödder, 2011; Vestergård, 2015]. These models are idealistic and potentially also unrealistic in a world in which there are clear incentives for scientists, their institutions and news media organisations to generate newsworthy scientific stories that may be achieved through omission of risks and limitations and exaggerations and relevance of research findings.

Despite there being competing interests for newsworthiness, accuracy and relevance of scientific news stories [Cassels et al., 2003; Caulfield et al., 2014; Haneef et al., 2015; Schwitzer, 2013], the responsibility for the production of inaccurate reporting is not straightforward. Science communication researchers have attributed misrepresentation of scientific research to a complex relationship between scientists, science communicators and journalists [Caulfield, 2005]. Facilitating the dynamic between scientists and journalists are communication specialists who work at universities, research institutes, academic journals and other organisations. These professionals are responsible for the production of press releases and media engagement activities. As research findings are one of the main commodities for research institutions, they have the potential to impact the institution's financial status and competitive rankings [Autzen and Weitkamp, 
2020]. Additionally, institutions that publish the most press releases tend to have the highest rankings [Autzen, 2014]. There is a clear incentive for institutions to publish high volumes of press releases about research findings that garner as much news coverage as possible. Additionally, exaggerating research findings in press releases is incentivised when the outcome is increased news media coverage of scientific research which has the potential to benefit researchers, their institution and the news media. Furthermore, experts have noted that the reliance on one source of information, such as an institution press release, grants a level of control of the news agenda to the researchers and their institution [Weitkamp and Eidsvaag, 2014].

As the scientific research and media landscapes continue to evolve including the increasing pressures on scientists to engage with the public and the demands on journalists to publish newsworthy stories about science with fewer resources, the interactions between these two fields require continual investigation. Additionally, the interdependencies between scientists, science communicators and journalists, including the complexities of communicating positivist lab-based science in a socially constructed environment, there is a need to conduct a detailed examination of the process and consequences of translating scientific research from academic journal articles to press releases to news media reporting.

\section{This case study}

As a significant proportion of news media is derived from press releases [Lewis et al., 2008] and the press release impacts on the accuracy of scientific news, [Sumner et al., 2016], this study sought to investigate in detail, the communication process in a well-known case of significant misrepresentation of scientific research in news media. This study was published in one of the most highly cited scientific journals worldwide and was the subject of a substantial number of international news reports at the time; many of which had the potential to influence health behaviours. The study was the subject of media scrutiny and featured in 'SBS News' which reported it as harmful, "Vitamin B3 claims slammed by obstetricians"' [SBS News, 2017].

The case at the centre of this paper is a journal article published in the New England Journal of Medicine in August 2017 titled "NAD deficiency, congenital malformations and niacin supplementation" [Shi et al., 2017] and the press release published by the researchers' institution "Historic discovery has the potential to prevent miscarriages and birth defects globally" [Victor Chang Cardiac Research Institute, 2017]. The journal article described a study that investigated the role of gene variations and niacin supplementation in the prevention of congenital malformations. Of note, mice bred with specific genetic mutations were used to assess the impact of niacin supplementation in the prevention of congenital malformations. The genetic mutations were modelled on genetic mutations found in human families that underwent genetic sequencing where there existed a history of congenital malformations.

While a major component of the study design was investigating the effects of niacin supplementation in mice, many news media reports implied the research had been undertaken in humans with direct health implications for women during 
pregnancy. As the niacin supplementation component of the study was undertaken in mice, the recommendations about vitamin supplementation in pregnant women were outside the scope of the findings of the research study. Additionally, recommendations made about niacin supplementation had potentially harmful consequences as an excessive consumption of niacin can be harmful to both pregnant women and their babies [The Royal Australian and New Zealand College of Obstetricians and Gynaecologists, 2017].

\section{Methods}

To explore in detail, the communication process that resulted in this scientific study being misrepresented in news reports, we analysed the journal article, the corresponding press release and all of the subsequent online news reports available through Google News to address the following question: how and where did misrepresentation of the scientific study take place? Additionally, we sought to address one research question that was specifically related to the news reporting: what communication techniques were used in the news reports that resulted in misrepresentation?

We searched Google News for the online news reports for a five-month period from August 2017 to December 2017 using key words such as "niacin", "vitamin B3", "Vegemite", "congenital malformations", "birth defects". The press release was issued on the $10^{\text {th }}$ of August and the vast majority of reports were published between $10^{\text {th }}$ and $12^{\text {th }}$ of August 2017. We restricted our search to Google News because it covers a vast range of news media sources [Filloux, 2013] and has been used previously in media analysis research as the single source of online news media coverage [Haneef et al., 2015; Young Lin and Rosenkrantz, 2017]. Google Chrome, Safari and Firefox were used to search for articles on Google News, all with refreshed browsers histories to ensure that all relevant articles were found and searching history did not affect the articles retrieved. After sourcing the journal article from the New England Journal of Medicine website [Shi et al., 2017], the press release from the Victor Chang website [Victor Chang Cardiac Research Institute, 2017] and the news media reports from Google News, each document was downloaded and imported into NVivo version 12. After reading each document, a preliminary coding framework was developed by the first author and refined through preliminary analysis and discussions with the other authors. The first author completed the quantitative and qualitative coding. For the quantitative coding, 10\% of articles were double coded by another author (LK) and codes and coding definitions were adjusted until agreement reached $80 \%$. For the qualitative coding, $10 \%$ of articles were double coded by LK and any disagreements were discussed and resolved and the same logic was applied to the rest of the qualitative coding by the first author.

\section{Development of coding framework for quantitative content analysis}

The coding framework involved developing preliminary codes to guide the analysis. This was based on reviewing the literature on the representation of scientific research in media (including the coding framework used by 'healthnewsreview.org' [HealthNewsReview.org, 2018] and by reading the journal article, press release and a subset of news media reports to tailor the coding to this specific study. An inductive approach followed the development of the 
preliminary codes and allowed for unexpected themes or the refinement of codes that developed during the analysis.

\section{Quantitative coding and analysis}

The coding framework included the following items: spin, buzz words, framing (positive, negative, balanced), a description of the study design, a description of the study population (mice and humans), description of the niacin supplementation trialled in mice, description of genetic sequencing undertaken in humans, a statement that study findings could not be translated to humans, clinical recommendations about vitamin supplementation, advice to consult a doctor for further information, the use of independent and non-independent expert commentators, the use of a patient narrative, the inclusion of funding information and a link to the journal article. Each of these items was coded either yes or no.

Spin has been defined in multiple ways in academic research [Bero, Chiu and Grundy, 2019]. We chose to use the following definition of spin: a way of reporting, for any motive whether intentional or unintentional, that emphasises that the beneficial effect of the intervention is greater than the actual results [Haneef et al., 2015]. We chose to use the following definition of buzzwords from the Oxford Dictionary: a word or phrase, often jargon, that is trendy in a particular context or at a specific time [Oxford English Dictionary, 2020]. Examples of buzzwords and phrases used in the press release and news media reporting included; 'historic medical breakthrough', 'landmark discovery', 'Australia's greatest ever medical achievements'. Framing can obfuscate objective reporting by highlighting and downplaying certain elements of stories in media which can impact the way readers interpret and relate to information [Birnbrauer, Frohlich and Treise, 2017; Entman, 1993] and impact readers' understanding of a story [Caulfield et al., 2014]. We chose to analyse whether each article was framed positively, negatively or in a balanced way.

For each article we also recorded whether there was a description of the study design, a description of what component of the research was undertaken in mice and what component was undertaken in humans and whether these specific research findings could be translated to humans. The type of clinical recommendations regarding vitamin supplementation that we analysed were both those that were directly related to this study and those that related to pregnancy in general. We chose to include both types of recommendations as they both have the potential to impact readers' health behaviour. We also recorded whether there was advice for readers to contact their doctor for more information and health advice about vitamin supplementation during pregnancy. Additionally, we recorded whether each article had independent expert commentators (i.e., those that were not involved with the study but who are experts in the area) or non-dependent expert commentators (those that were involved with the study either as authors or representatives from the researchers' institute). We counted information about the funding sources as any information about what organisations funded the research. Information about how to access the journal article was coded as 'yes' if a link to the article was included, not just mentioning the name of the journal. We also coded whether news reports used a patient narrative. Narratives are important for storytelling and for readers' understanding of the relevance of an issue. 


\section{Qualitative analysis}

The qualitative analysis investigated in more depth, the data coded for the quantitative content analysis. The coded data was further analysed to determine, for example, in what context and for what effect: spin, buzz words and framing were used, whether the omissions or inclusions about the study design, the study population and what components of the research were done in mice and humans resulted in misrepresentation, the extent to which: information about study findings could be translated to humans, clinical recommendations about vitamin supplementation during pregnancy and advice to consult a doctor may contribute to potentially harmful clinical behaviours or outcomes for readers. The impact of independent and non-dependent commentators, patient narratives, funding information and access to the journal article were also reviewed to understand the role these played in relation in the subjectivity of the story.

\section{Results}

We identified 60 unique news reports from 48 separate news organisations and websites. The news sources included organisations such as the British Broadcasting Corporation (BBC) and the Australian Broadcasting Corporation (ABC), as well as lesser-known technology-focused and health-related websites such as Gizmodo and Body and Soul. The journal article, the press release and the news reports were coded by the first author. The results of content analysis are presented in four groups of themes that emerged in the qualitative analysis. Table 1 summarises findings from the content analysis. The qualitative analysis is presented as themes and illustrated with quotes.

\section{Content analysis}

\section{Theme 1, Sensationalism}

The journal article did not include spin in its title, or in the article itself, nor did it include buzz words and presented a balanced frame. The press release used spin in both the headline and body of the press release, included buzz words from experts and introduced positive framing. The majority of news reports included spin in the body of the article $(68 \%)$ and buzz words $(87 \%)$. The majority $(71 \%)$ of news reports were framed positively.

\section{Theme 2, Misrepresentation}

The journal article contained a description of the: study design; study population as including both mice and humans; niacin supplementation being undertaken in mice and genetic sequencing being undertake in humans. The press release contained a description of the study design but did not describe the study design as including both mice and humans. It described the niacin supplementation as being undertaken in mice but did not describe the genetic sequencing being undertaken in humans. The majority $(87 \%)$ of news reports described the study design and most $(62 \%)$ described the niacin supplementation being undertaken in mice. Around half (57\%) of the news reports described the study population as including both mice and humans. A similar proportion (56\%) described the genetic sequencing being undertaken in humans. 


\begin{tabular}{|c|c|c|c|c|c|c|c|}
\hline \multirow[b]{3}{*}{$\begin{array}{l}\text { Themes identified in qualitative } \\
\text { analysis }\end{array}$} & \multicolumn{7}{|l|}{ Results of content analysis } \\
\hline & \multirow[t]{2}{*}{ Codes quantified in quantitative analysis } & \multirow[t]{2}{*}{ Journal article } & \multirow[t]{2}{*}{ Press release } & \multicolumn{2}{|l|}{ News reports } & \multicolumn{2}{|l|}{ News reports } \\
\hline & & & & Yes frequency & Yes \% & No frequency & No $\%$ \\
\hline \multirow[b]{9}{*}{ Theme 1 -Sensationalism } & Spin in headline & No & Yes & 29 & $48 \%$ & 31 & $52 \%$ \\
\hline & Spin in body of article & No & Yes & 36 & $68 \%$ & 24 & $32 \%$ \\
\hline & Buzz words & No & Yes & 52 & $87 \%$ & 8 & $13 \%$ \\
\hline & Buzz words used by (only) experts & - & Yes & 13 & $22 \%$ & 43 & $78 \%$ \\
\hline & Buzz words used by (both) experts and journalists & - & No & 39 & $65 \%$ & 21 & $61 \%$ \\
\hline & Buzz words used by (only) journalists & - & No & 0 & $0 \%$ & 60 & $100 \%$ \\
\hline & Positive framing & No & Yes & 43 & $71 \%$ & 17 & $29 \%$ \\
\hline & Balanced framing & Yes & No & 10 & $17 \%$ & 50 & $83 \%$ \\
\hline & Negative framing & No & No & 7 & $12 \%$ & 53 & $88 \%$ \\
\hline \multirow[b]{4}{*}{ Theme 2 - Misrepresentation } & Described the study design (at all) & Yes & Yes & 52 & $87 \%$ & 8 & $13 \%$ \\
\hline & Described study population as included (both) mice and humans & Yes & No & 34 & $57 \%$ & 18 & $43 \%$ \\
\hline & Described niacin supplementation as being done in mice & Yes & Yes & 37 & $62 \%$ & 15 & $38 \%$ \\
\hline & Described genetic sequencing as being done in humans & Yes & No & 34 & $56 \%$ & 18 & $44 \%$ \\
\hline \multirow[b]{3}{*}{ Theme 3 - Clinical recommendations } & Stated that study findings cannot be translated to humans & No & No & 36 & $60 \%$ & 24 & $40 \%$ \\
\hline & Clinical recommendations made (whether based on this study or something else) & Yes & Yes & 53 & $88 \%$ & 7 & $12 \%$ \\
\hline & Advised to consult doctor for more information & - & No & 56 & $7 \%$ & 4 & $93 \%$ \\
\hline \multirow[b]{6}{*}{ Theme 4 - Subjectivity } & Included both independent and non-independent expert commentators & - & No & 28 & $47 \%$ & 32 & $53 \%$ \\
\hline & Included non-independent expert commentators only & - & Yes & 27 & $45 \%$ & 33 & $55 \%$ \\
\hline & Included no expert commentators & - & No & 5 & $8 \%$ & 55 & $92 \%$ \\
\hline & Included a patient narrative & - & No & 10 & $17 \%$ & 50 & $83 \%$ \\
\hline & Included funding information & Yes & Yes & 10 & $17 \%$ & 50 & $83 \%$ \\
\hline & Included a link to the journal article & - & Yes & 15 & $25 \%$ & 45 & $75 \%$ \\
\hline
\end{tabular}

Table 1. Content analysis.

\section{Theme 3, Clinical recommendations}

The journal article did not explicitly state that study findings could not be translated to humans and included clinical recommendations relevant to human health. The press release did not state that findings were not directly transferrable to humans. Clinical recommendations were made about human health and there was no advice for people to seek professional advice if readers wanted more information. In the news reports, while most (60\%) stated that the study findings could not be translated to humans, the vast majority (88\%) of articles included clinical recommendations about vitamin supplementation. Few news reports (7\%) advised readers to consult their doctor for more information.

\section{Theme 4, Subjectivity}

The journal article did not contain commentary or patient narratives and there was a disclosure about study funding. The press release included non-independent commentators only (i.e., those with a direct connection to the study), no patient narrative, disclosure of study funding and a link to the journal article. In the news reports, around half $(47 \%)$ included both independent and non-independent expert commentators. A similar proportion (45\%) included non-independent expert commentators only. Seventeen percent of news reports included a patient narrative. The same proportion (17\%) included funding information and a quarter $(25 \%)$ included a link to the journal article. 
Table 1 represents the results of the content analysis. The results of the content analysis were grouped into themes that were explored in more detail in the qualitative analysis.

\section{Qualitative analysis}

In the qualitative analysis, we explored each theme in more detail based on further analysis of the coded quantitative data.

\section{Sensationalism}

In the translation of information from the journal article to the press release to the news media reporting, the use of spin, buzzwords and positive framing were introduced in the press release and were in many cases, directly translated in news media reports. This direct translation is evident by the direct quoting of slabs of text from the press release to the news reports. In the example below, the extrapolation of the research findings to reduce miscarriages and birth defects in the press release is an example of spin. The word 'landmark' is an example of a buzz word and the general positivity without any discussion of limitations, such as the study being undertaken in mice, is an example of positive framing.

\footnotetext{
"The ramifications are likely to be huge. This has the potential to significantly reduce the number of miscarriages and birth defects around the world, and I do not use those words lightly," says Professor Dunwoodie. The landmark study found that a deficiency in a vital molecule, known as NAD, can prevent a baby's organs from developing correctly in the womb.

(Historic discovery has the potential to prevent miscarriages and birth defects globally, Victor Chang press release, August 2017)

"The ramifications are likely to be huge," said the study's senior researcher Professor Sally Dunwoodie at the Victor Chang Institute... "This has the potential to significantly reduce the number of miscarriage and birth defects around the world, and I do not use those words lightly."

(Sydney Morning Herald, 17 August 2017)
}

However even with spin, buzzwords and positive framing used in the press release, not all news media reports employed these literary techniques. Some news articles $(32 \%)$ presented information with no spin and roughly half $(47 \%)$ of articles had both non-independent and independent expert commentators. The news reports that were framed negatively focused on the potentially harmful health consequences of the misleading information. Below is an excerpt from a news report with negative framing.

The Royal Australian and New Zealand College of Obstetricians and Gynaecologists says the "extraordinary" suggestions by researchers at the Victor Chang Institute were based on a small mouse study and have the potential to do more harm than good.

(SBS News, 11 August 2017) 


\title{
Misrepresentation
}

The description of the study design in the journal article was clear and included both the human and mouse components of the research. The journal article described the human and mouse components of the research:

\begin{abstract}
We used genomic sequencing to identify potentially pathogenic gene variants in families in which a person had multiple congenital malformations. We tested the function of the variant by using assays of in vitro enzyme activity and by quantifying metabolites in patient plasma. We engineered mouse models with similar variants using the CRISPR (clustered regularly interspaced short palindromic repeats)-Cas 9 system.

(NAD deficiency, congenital malformations and niacin supplementation,

New England Journal of Medicine 2017)
\end{abstract}

However, the description of the study design in the press release did not reflect the journal article as the human component of the research was omitted. Additionally, the press release included information about how the study would have direct human health benefits without describing any limitations of extrapolating mouse research to humans. The press release indicates that the findings from mouse research will have human translations:

\footnotetext{
Scientists at the Victor Chang Institute have discovered simply boosting levels of this nutrient during pregnancy can potentially prevent recurrent miscarriages and birth defects.

(Historic discovery has the potential to prevent miscarriages and birth defects globally, Victor Chang press release, August 2017)
}

One news report indicated that niacin supplementation may reduce birth defects in humans:

\footnotetext{
The study, published in the New England Journal of Medicine, found that deficiency in a key molecule among pregnant women stopped embryos and babies' organs from developing correctly in the womb, but could be treated by taking the dietary supplement vitamin B3, also known as niacin.

(Business Insider, 10 August 2017)
}

However, despite the implied direct translation of mouse research to humans, more than half of the news media reports included information about both the human and mice components of the research. Additionally, more than half of the news media reports included information about how the research findings cannot be directly translated to humans.

The study was a preclinical trial, and the results will need to be replicated in humans before doctors can recommend vitamin B3 supplements to pregnant women, but the results are certainly promising.

(IFL Science, 10 August 2017) 


\section{Clinical recommendations}

Toward the end of the journal article, there is a "theorisation" made about the use of vitamin supplementation, but it is clearly relating to the specific families who were involved in the genetic sequencing component of the research rather than the population more generally.

We theorize that supplementation with high-dose niacin (140 mg per day, which is 10 times the U.S. recommended daily allowance for women) before and during pregnancy might prevent recurrence of disease in these four families. It is also possible that niacin supplementation may benefit the speech and developmental delays in the surviving patients.

(NAD deficiency, congenital malformations and niacin supplementation,

New England Journal of Medicine 2017)

However, the information in the press release about vitamin supplementation could be interpreted as relevant to the population more broadly and could be interpreted as immediately applicable to human health.

Just like we now use folate to prevent spina bifida, Professor Dunwoodie's research suggests that it is probably best for women to start taking vitamin B3 very early on, even before they become pregnant.

(Historic discovery has the potential to prevent miscarriages and birth defects globally, Victor Chang press release, August 2017)

Although most reports made recommendations of some sort about vitamin supplementation, other reports did make it clear that this research study could not be translated directly into recommendations about vitamin supplementation.

\footnotetext{
Although this is a potentially exciting finding in a very emotive area, it is important to bear in mind that this result is based on studies in mice, and we will need a full research project in women to evaluate the cause and effect of any lack of this vitamin in humans.

(Huffington Post U.K., 10 August 2017)
}

However, like the press release, some news media reports did make recommendations that could have harmful consequences.

The results published in the New England Journal of Medicine suggested giving women niacin supplements before and during pregnancy could significantly cut the risk of miscarriage and congenital defects.

(Irish Times, 12 August 2017)

\section{Subjectivity}

As with framing, patient narratives can add weight to certain aspects of a story which can resonate with the reader. Patient narratives can be helpful if they assist readers to understand issues, but they can be misleading if they do not accurately 
represent the facts of a story. In this case study, the use of a patient narrative might assist readers in understanding the types of congenital malformations potentially prevented with niacin supplementation. However, because this research was undertaken in mice and not directly translatable to humans, a patient narrative might be misleading, suggesting to readers that all congenital malformations are prevented via niacin supplementation. Additionally, subjectivity was present in news reports where journalists used comments from non-independent experts. Without independent expert commentary, there is a lack of objectivity and critical reflection about the potential translation of the research findings.

\begin{abstract}
Charlotte Scaife was just one day old when her parents found out the heartbreaking news - the middle part of their baby's heart hadn't formed properly and there were multiple holes in her heart... [parent of child (Charlotte) with congenital birth defect] "I wish they'd known about it and the information had been released two years ago or three years ago, and then maybe we wouldn't be going through this."

(Huffington Post Australia, 11 August 2017)
\end{abstract}

Despite the press release only including non-independent expert commentators, both non-independent and independent expert commentators were included in almost half of the news media reports, providing evidence that journalists sought additional information to that which was provided in the press release and original journal article.

The press release provided a comment from a non-independent expert:
"We believe that this breakthrough will be one of our country's greatest medical discoveries. It's extremely rare to discover the problem and provide a preventive solution at the same time. It's actually a double breakthrough," said Professor Graham. (Historic discovery has the potential to prevent miscarriages and birth defects globally, Victor Chang press release, August 2017)

Some news reports sought independent experts to comment on the study:

\begin{abstract}
Dr Katie Morris, an expert in maternal foetal medicine at the University of Birmingham, said: "While exciting, this discovery cannot be translated into recommendations for pregnant women, who at most may be deficient in vitamin $B 3$. (BBC, 10 August 2017)
\end{abstract}

\title{
Discussion
}

In this study, we used quantitative and qualitative content analysis to investigate the translation of information from a scientific journal article, to the corresponding press release to the subsequent online news reporting of a known case of misrepresentation of scientific research in news media. Specifically, we sought to understand how and where misrepresentation of the scientific study took place and what communication techniques were used by journalists in media reports.

Results showed that sensationalism was present in the press release and was reflected in a large proportion of the news reporting via the use of reporting techniques such as spin, buzz words and positive framing. Misrepresentation of 
information in the form of inadequate descriptions of the study design and the study populations was translated from the press release to the news reports. In addition, potentially harmful clinical recommendations that featured in the press release were present in a large proportion of the news reports by way of unrealistic extrapolation of findings from mice to humans, a lack of discussion around the limitations of the research and a lack of further advice to consult a doctor for additional information.

The press release included commentary by non-independent experts, and this was reflected in many of the news reports. However, many journalists also sourced independent expert comment. Additionally, given the press release contained spin, buzz words, positive framing, non-independent expert commentators, a brief and inaccurate description of the study design, implied that the study findings in mice could be translated to humans, it is noteworthy that many journalists sought additional information and presented a more balanced account of the research than what was contained in the press release. Therefore, some journalists made deliberate efforts to avoid the misrepresentation that was present in the press release.

These findings highlight that in this case, mechanisms that may result in exaggerations and misrepresentation of scientific research can be directly traced back to the press release. The findings were that the press release and a proportion of the news reports had exaggerated the benefits via the extrapolation of a mouse study to humans and the absence of limitations such as the need for further research in humans and discussion about the potential risks resulting from excessive consumption of vitamin supplementation during pregnancy. This is in line with prior science communication research which has highlighted that scientific studies when written about it media, often exaggerate findings and downplay risks and limitations [Cassels et al., 2003; Caulfield et al., 2014; Haneef et al., 2015; Schwitzer, 2013]. Although exaggeration of findings and downplaying limitations and risks are unsurprising, the instances of journalists seeking diverse views and critical reflections of the study from independent sources are noteworthy.

In the context of research findings being a core commodity that impacts an institution's financial and ranking successes [Autzen and Weitkamp, 2020] it is significant that the press release was produced by the scientific researchers' institution and that this press release is where the exaggerations about findings and lack of information about risks originated. When thinking about the medialisation of science, there is both a clear and mutually beneficial relationship between scientists and the media. As the study findings were exaggerated, the story was able to be framed as a "breakthrough" garnering significant media attention for the potential benefit of the researchers, their institution and the media with the publication of many "click-bait" articles with headlines such as "Vegemite and pregnancy: niacin could prevent miscarriages" (Daily Telegraph, August 2017). As the public look to media to make sense of complex topics [Scheufele and Lewenstein, 2005], the framing of this scientific research in the press release and in the news media yielded some potentially harmful sense making interpretations followed by responsive backlash from experts in the field who labelled the researchers suggestions as having "the potential to do more harm than good" [SBS News, 2017]. 
From a theoretical perspective, both the press release and those news reports that used non-independent commentators and omitted key information required to understand the study were in line with a PUS paradigm of science communication. As an example, in some cases the description of the study was oversimplified to the point where it was not possible to understand how the study was conducted or what the implications might be for pregnant women. Despite the omission of information about the research study, specifically the lack of description of the study design and how both mice and humans were used, it is important to note that a proportion of the news media reports did seek information from sources outside of the press release to achieve a more informed, objective and accurate account of the scientific study. For example, some news media reports included both independent and non-dependent commentaries in addition to a detailed explanation of the study design that explained the role of both humans and mice in the study in addition to an explanation about how the study cannot yet be translated to human health and that further research is needed to before advice about niacin supplementation can be made. A portion of journalists wrote news reports in line with PEST theory by providing readers with sufficient and objective information which gave them the opportunity to understand the scientific study and make their own judgements about what the findings could mean. This more investigative and critical work by the journalists added a more objective and contextualised aspect to the story. These journalists were not just informing audiences about the 'wonders of science' but communicating diverse views and critical reflections. This is especially remarkable given that journalists have a strong trust in science, their scientific sources and are pressured to adhere to scientific values [Vogler and Schäfer, 2020] which is in addition to being under resourced and there being few science journalists with specialised skills to critique a scientific study [Barel-Ben David, Garty and Baram-Tsabari, 2020]. However, just as journalists critique politicians and policy, they too can critique scientists and science [Rensberger, 2009]. This would be made easier if journalists regained some of the scientific expertise and resourcing that has been lost as newsrooms have declined in overall staff including science journalists [Brüggemann, Lörcher and Walter, 2020].

A challenge exists in communicating via news media the relevance to human health of positivist lab based pre-clinical science where the scientific environment is highly controlled, and the research subjects are animals. Pre-clinical research can have direct relevance to human health in the long-term otherwise it would not be undertaken. However, making this relevance obvious without explaining all the caveats and further steps in the research process would likely result in pre-clinical discoveries becoming less newsworthy. Pre-clinical lab-based studies are an essential step in the formulation of evidence and are imperative to building the case for the next phase of research which, in this case study example, could be in humans. Therefore, if pre-clinical lab science is to be reported in news media, there exists a challenge whereby the findings need to be comprehensible and accurate but at the same time, relatable to readers. It is this tension, that could in part, be responsible for some of the misrepresentation of the study in the press release. On one hand, the researchers need to demonstrate 'real-world' impact to make their future research possible and therefore, an incentive to minimise the caveats of their research findings to make their research newsworthy. Conversely, demonstrating 'real-world' impact could be more difficult if press releases include detailed information about the limitations of the research and the additional 
research required to determine the relevance of findings to human health. Therefore, a potential interpretation of the motivations of the researchers in the misrepresentation of the findings in the press release, is that they may not have been aware of the dangers of misleading the public that can occur whilst trying to communicate the future potential of their research. In other words, attempting to strike a balance between the conservative language of scientists and the importance of media attention for the goal of generating further research funding and opportunities.

Additionally, the medialisation of science is important amidst the current global pandemic with COVID-19 receiving extensive and ongoing media coverage across the world since January 2020. COVID-19 has seen the world's population rely on media for the dissemination and sense making of constantly evolving scientific information with news reports about the pandemic having major impacts on readers' beliefs about its origins and their country's policy responses and crisis politicisation [Pearman et al., 2021]. Some changes to scientific publishing that have ongoing consequences for science journalism that have occurred since January 2020 include: a dramatic increase in the number of published academic journal articles (not just on COVID-19 but on all topics and especially those in health related disciplines) and a significant increase in articles being made available prior to peer review [Else, 2020]. Both of these outcomes add more challenges for journalists who are overloaded with information to report on and who are now critiquing research that has not yet been through peer review.

\section{Limitations}

The use of one case study as a means of investigating a phenomenon provides rich data but means that the results may not be generalisable for understanding where and how misrepresentation of scientific information occurs in communication pathways in all cases. The use of Google News as a single source of online news means that some online news reports about this study may not have been captured. Whilst we developed the coding framework collaboratively and double coded $10 \%$ of reports and reached an $80 \%$ agreement, there is still some subjectivity to interpretation of the variables that were coded.

\section{Conclusion}

Science communication, and especially science journalism is about reporting truthfully. It is about going beyond hypotheses, data and breakthroughs and looking at the scientists, their conflicts, their funding and other issues that impact the production of science [Borel, 2015]. In an ideal world, there should be no need for scientists, science communicators or science journalists to oversell research findings, exaggerate benefits, omit limitations and risks and fail to describe scientific research in a way that readers can understand. However, there are pressures on scientists to demonstrate the 'real-world' impact of their work, on science communicators to generate media attention and on journalists to produce newsworthy content about science. This 'pressure cocktail' can result in misrepresentation of science that could lead to harmful health behaviours and public misunderstandings and distrust in science. It is for these reasons that those producing the science, the press releases and the news must work together to communicate truthful and objective science to society. Utilising the PEST paradigm, journalists would synthesise and scrutinise research findings, interview 
independent experts and present science in more than one simplistic science-dominated side to a story but in a contextualised-scientific way in which readers have enough information to judge the scientific research for themselves. However, given the constraints on journalists in both time and resources, it is unrealistic to expect this to be possible for every scientific study that is reported in news media. Given that it is a reality that journalists will need to rely, at least in part, on press releases, it is imperative that press releases are written with the same level of journalistic integrity as the PEST paradigm idealises.

This case study highlights the implications of what can happen when the translation of science from a journal article to a press release to the news media reporting is confounded by pressures faced by scientists, their institutions and news media. We hypothesise the lack of objectivity in this case to be a result of the pressures on journalists, scientists and their institutions which has led to a mutually beneficial relationship between these actors that can prioritises newsworthiness ahead of scientific objectivity to the detriment of public health. There must be an ongoing priority for scientific information to be represented in media in a way that is helpful, not harmful as entire populations try to make sense of the constantly evolving scientific advice related to COVID-19 and future public health crises. In the current scientific, science communication and journalistic climates, in combination with the way that populations are relying on media for their sense making of COVID-19, we acknowledge the following tensions faced by scientists, science communicators and journalists: not to exaggerate, oversimplify and or omit essential information for the sake of media attention and to equip the audience with the information required to understand a scientific study including contextualised information and independent commentary. This approach is especially important in areas of public mistrust such as those that have serious consequences for public health for example, COVID-19 vaccinations. Scientists, science communicators and journalists have an obligation to frame science as interesting and newsworthy without jeopardizing the truth.

\section{References}

Autzen, C. (2014). 'Press releases - the new trend in science communication'. JCOM 13 (03), C02. https: //doi .org/10.22323/2.13030302.

Autzen, C. and Weitkamp, E. (2020). 'Science communication and public relations: beyond borders'. In: Science Communication. Ed. by A. Leßmöllmann, M. Dascal and T. Gloning. Vol. 17. Handbooks of Communication Science. Boston, MA, U.S.A. and Berlin, Germany: De Gruyter Mouton, pp. 465-484. https://doi.org/10.1515/9783110255522-022.

Barel-Ben David, Y., Garty, E. S. and Baram-Tsabari, A. (2020). 'Can scientists fill the science journalism void? Online public engagement with science stories authored by scientists'. PLoS ONE 15 (1), e0222250. https://doi.org/10.1371/journal.pone.0222250.

Barthel, M. (2017). 'Despite subscription surges for largest U.S. newspapers, circulation and revenue fall for industry overall'. Pew Research Center. URL: https://www . pewresearch.org/fact-tank/2017/06/01/circulation-an d-revenue-fall-for-newspaper-industry/.

Bero, L., Chiu, K. and Grundy, Q. (2019). 'The SSSPIN study — spin in studies of spin: meta-research analysis'. BMJ 367, 16202.

https://doi.org/10.1136/bmj.16202. 
Besley, J. C. and Nisbet, M. (2013). 'How scientists view the public, the media and the political process'. Public Understanding of Science 22 (6), pp. 644-659. https://doi.org/10.1177/0963662511418743.

Birnbrauer, K., Frohlich, D. O. and Treise, D. (2017). 'Inconsistencies in reporting risk information: a pilot analysis of online news coverage of West Nile Virus'. Global Health Promotion 24 (3), pp. 14-22. https://doi.org/10.1177/1757975915594603.

Borel, B. (2015). 'The problem with science journalism: we've forgotten that reality matters most'. The Guardian. URL: https://www . theguardian. com/media/2015 /dec/30/problem-with-science-journalism-2015-reality-kevin-folta.

Brüggemann, M., Lörcher, I. and Walter, S. (2020). 'Post-normal science communication: exploring the blurring boundaries of science and journalism'. JCOM 19 (03), A02. https: //doi .org/10.22323/2.19030202.

Burns, T. W., O'Connor, D. J. and Stocklmayer, S. M. (2003). 'Science communication: a contemporary definition'. Public Understanding of Science 12 (2), pp. 183-202. https://doi.org/10.1177/09636625030122004.

Butler, D. (2016). 'Dutch lead European push to flip journals to open access'. Nature 529 (7584), p. 13. https: //doi.org/10.1038/529013a.

Cassels, A., Hughes, M. A., Cole, C., Mintzes, B., Lexchin, J. and McCormack, J. P. (2003). 'Drugs in the news: an analysis of Canadian newspaper coverage of new prescription drugs'. CMAJ 168 (9), pp. 1133-1137. PMID: 12719316. URL: https://www. cmaj.ca/content/168/9/1133.

Caulfield, T. (2005). 'Popular media, biotechnology, and the "cycle of hype"'. Houston Journal of Health Law \& Policy 5 (2), pp. 213-233.

Caulfield, T., Clark, M. I., McCormack, J. P., Rachul, C. and Field, C. J. (2014). 'Representations of the health value of vitamin D supplementation in newspapers: media content analysis'. BMJ Open 4 (12), e006395. https://doi.org/10.1136/bmjopen-2014-006395.

Else, H. (2020). 'How a torrent of COVID science changed research publishing — in seven charts'. Nature 588 (7839), p. 553. https://doi.org/10.1038/d41586-020-03564-y.

Entman, R. M. (1993). 'Framing: toward clarification of a fractured paradigm'. Journal of Communication 43 (4), pp. 51-58. https://doi.org/10.1111/j.1460-2466.1993.tb01304.x.

- (2007). 'Framing bias: media in the distribution of power'. Journal of Communication 57 (1), pp. 163-173. https://doi.org/10.1111/j.1460-2466.2006.00336.x.

Erdal, I. J. (2019). 'Convergence in/of journalism'. In: Oxford Research Encyclopedia of Communication. Oxford, U.K.: Oxford University Press. https://doi.org/10.1093/acrefore/9780190228613.013.793.

Filloux, F. (2013). 'Google News: the secret sauce'. The Guardian. URL: https://www . theguardian. com/technology/2013/feb/25/1.

Fuoco, R. (2021). 'How to get media coverage and boost your science's impact'. Nature. https://doi.org/10.1038/d41586-021-02067-8.

Geller, G., Bernhardt, B. A. and Holtzman, N. A. (2002). 'The media and public reaction to genetic research'. JAMA 287 (6), p. 773. https://doi .org/10.1001/jama.287.6.773-JMS0213-3-1. PMID: 11851549.

Glynn, D. (2016). 'Why early career researchers should care about public engagement'. Times Higher Education.

URL: https://www.timeshighereducation.com/blog/why-early-career-rese archers-should-care-about-public-engagement. 
Godlee, F., Smith, J. and Marcovitch, H. (2011). 'Wakefield's article linking MMR vaccine and autism was fraudulent'. BMJ 342, c7452.

https://doi.org/10.1136/bmj.c7452.

Gross, A. G. (1994). 'The roles of rhetoric in the public understanding of science'. Public Understanding of Science 3 (1), pp. 3-23.

https://doi.org/10.1088/0963-6625/3/1/001.

Haneef, R., Lazarus, C., Ravaud, P., Yavchitz, A. and Boutron, I. (2015). 'Interpretation of results of studies evaluating an intervention highlighted in Google Health News: a cross-sectional study of news'. PLOS ONE 10 (10), e0140889. https://doi.org/10.1371/journal.pone.0140889.

Hargreaves, I. (2003). Journalism: truth or dare? Oxford, U.K.: Oxford University Press.

HealthNewsReview.org (2018). Our review criteria. URL: https://www .healthnewsreview .org/about-us/review-criteria/.

Johnson, T. (1998). 'Shattuck lecture - Medicine and the media'. The New England Journal of Medicine 339 (2), pp. 87-92. https://doi.org/10.1056/NEJM199807093390206.

Kamenova, K. (2017). 'Media portrayal of stem cell research: towards a normative model for science communication'. Asian Bioethics Review 9 (3), pp. 199-209. https://doi.org/10.1007/s41649-017-0026-8.

Kata, A. (2010). 'A postmodern Pandora's box: anti-vaccination misinformation on the Internet'. Vaccine 28 (7), pp. 1709-1716. https://doi.org/10.1016/j.vaccine.2009.12.022.

King, G., Schneer, B. and White, A. (2017). 'How the news media activate public expression and influence national agendas'. Science 358 (6364), pp. 776-780. https://doi.org/10.1126/science.aao1100.

Landhuis, E. (2016). 'Scientific literature: information overload'. Nature 535 (7612), pp. 457-458. https: //doi .org/10.1038/nj7612-457a.

Le Masurier, M. (2015). 'What is slow journalism?' Journalism Practice 9 (2), pp. 138-152. https://doi.org/10.1080/17512786.2014.916471.

Lewis, J., Williams, A. E., Franklin, R. A., Thomas, J. and Mosdell, N. (2008). The quality and independence of British journalism. Tracking the changes over 20 years. Cardiff, U.K.: Cardiff University.

Mellor, F. (2015). 'Non-news values in science journalism'. In: Absence in science, security and policy: from research agendas to global strategy. Ed. by B. Rappert and B. Balmer. London, U.K.: Palgrave Macmillan, pp. 93-113.

https://doi.org/10.1057/9781137493736_5.

Metcalfe, J. (2019). 'Comparing science communication theory with practice: an assessment and critique using Australian data'. Public Understanding of Science 28 (4), pp. 382-400. https : //doi .org/10.1177/0963662518821022.

Motta, M. and Stecula, D. (2021). 'Quantifying the effect of Wakefield et al. (1998) on skepticism about MMR vaccine safety in the U.S.' PLoS ONE 16 (8), e0256395. https://doi.org/10.1371/journal.pone. 0256395.

Newman, N., Fletcher, R., Kalogeropoulos, A. and Kleis Nielsen, R. (2019). Reuters Institute Digital News Report 2019. Oxford, U.K.: Reuters Institute for the Study of Journalism, University of Oxford.

URL: http://www.digitalnewsreport.org/.

O'Connor, C. and Joffe, H. (2014). 'Gender on the brain: a case study of science communication in the new media environment'. PLOS ONE 9 (10), e110830. https://doi.org/10.1371/journal. pone.0110830. 
O'Regan, T. and Young, C. (2019). 'Journalism by numbers: trajectories of growth and decline of journalists in the Australian census 1961-2016'. Media International Australia 172 (1), pp. 13-32. https://doi.org/10.1177/1329878x19862935.

Ofcom (2019). News consumption in the UK: 2019 report. URL: https://www.of com.org.uk/__data/assets/pdf_file/0027/157914/uknews-consumption-2019-report.pdf.

Oliver, M. B., Raney, A. A. and Bryant, J., eds. (2019). Media effects: advances in theory and research. 4 th ed. New York, NY, U.S.A.: Routledge. https://doi.org/10.4324/9780429491146.

Oxford English Dictionary (2020). Buzzword. URL: https://www. lexico.com/en/definition/buzzword.

Pearman, O., Boykoff, M., Osborne-Gowey, J., Aoyagi, M., Gammelgaard Ballantyne, A., Chandler, P., Daly, M., Doi, K., Fernández-Reyes, R., Jiménez-Gómez, I., Nacu-Schmidt, A., McAllister, L., McNatt, M., Mocatta, G., Petersen, L. K., Simonsen, A. H. and Ytterstad, A. (2021). 'COVID-19 media coverage decreasing despite deepening crisis'. The Lancet Planetary Health 5 (1), E6-E7. https://doi .org/10.1016/S2542-5196(20)30303-X.

Phillips, D. P., Kanter, E. J., Bednarczyk, B. and Tastad, P. L. (1991). 'Importance of the lay press in the transmission of medical knowledge to the scientific community'. The New England Journal of Medicine 325 (16), pp. 1180-1183. https://doi.org/10.1056/NEJM199110173251620.

Rawat, S. and Meena, S. (2014). 'Publish or perish: where are we heading?' Journal of Research in Medical Sciences 19 (2), pp. 87-89. PMID: 24778659.

Rensberger, B. (2009). 'Science journalism: too close for comfort'. Nature 459 (7250), pp. 1055-1056. https://doi.org/10.1038/4591055a.

Rödder, S. (2011). 'Science and the mass media - 'Medialization' as a new perspective on an intricate relationship'. Sociology Compass 5 (9), pp. 834-845. https://doi.org/10.1111/j.1751-9020.2011.00410.x.

SBS News (2017). 'Vitamin B3 claims slammed by obstetricians'. URL: https://www.sbs.com.au/news/article/vitamin-b3-claims-slammed-b y-obstetricians/kyua75v1f.

Schäfer, M. S. (2009). 'From public understanding to public engagement: an empirical assessment of changes in science coverage'. Science Communication 30 (4), pp. 475-505. https ://doi.org/10.1177/1075547008326943.

Scheufele, D. A. and Lewenstein, B. V. (2005). 'The public and nanotechnology: how citizens make sense of emerging technologies'. Journal of Nanoparticle Research 7 (6), pp. 659-667. https://doi .org/10.1007/s11051-005-7526-2.

Schwitzer, G. (2013). 'Addressing tensions when popular media and evidence-based care collide'. BMC Medical Informatics and Decision Making 13 (Suppl 3), S3. https: //doi .org/10.1186/1472-6947-13-s3-s3.

Seale, C. (2003). 'Health and media: an overview'. Sociology of Health $\mathcal{E}$ Illness 25 (6), pp. 513-531. https://doi.org/10.1111/1467-9566.t01-1-00356.

Selvaraj, S., Borkar, D. S. and Prasad, V. (2014). 'Media coverage of medical journals: do the best articles make the news?' PLOS ONE 9 (1), e85355. https://doi.org/10.1371/journal. pone.0085355.

Shearer, E. (2018). 'Social media outpaces print newspapers in the U.S. as a news source'. Pew Research Center.

URL: https://www . pewresearch.org/fact-tank/2018/12/10/social-media-o utpaces-print-newspapers-in-the-u-s-as-a-news-source/. 
Shi, H., Enriquez, A., Rapadas, M., Martin, E. M. M. A., Wang, R., Moreau, J., Lim, C. K., Szot, J. O., Ip, E., Hughes, J. N., Sugimoto, K., Humphreys, D. T., McInerney-Leo, A. M., Leo, P. J., Maghzal, G. J., Halliday, J., Smith, J., Colley, A., Mark, P. R., Collins, F., Sillence, D. O., Winlaw, D. S., Ho, J. W. K., Guillemin, G. J., Brown, M. A., Kikuchi, K., Thomas, P. Q., Stocker, R., Giannoulatou, E., Chapman, G., Duncan, E. L., Sparrow, D. B. and Dunwoodie, S. L. (2017). 'NAD deficiency, congenital malformations, and niacin supplementation'. The New England Journal of Medicine 377 (6), pp. 544-552. https://doi.org/10.1056/nejmoa1616361.

Shih, T.-J., Wijaya, R. and Brossard, D. (2008). 'Media coverage of public health epidemics: linking framing and issue attention cycle toward an integrated theory of print news coverage of epidemics'. Mass Communication and Society 11 (2), pp. 141-160. https://doi.org/10.1080/15205430701668121.

Sturgis, P. and Allum, N. (2004). 'Science in society: re-evaluating the deficit model of public attitudes'. Public Understanding of Science 13 (1), pp. 55-74. https://doi.org/10.1177/0963662504042690.

Sumner, P., Vivian-Griffiths, S., Boivin, J., Williams, A., Bott, L., Adams, R., Venetis, C. A., Whelan, L., Hughes, B. and Chambers, C. D. (2016).

'Exaggerations and caveats in press releases and health-related science news'. PLOS ONE 11 (12), e0168217. https://doi.org/10.1371/journal.pone.0168217.

Taylor, J. W., Long, M., Ashley, E., Denning, A., Gout, B., Hansen, K., Huws, T., Jennings, L., Quinn, S., Sarkies, P., Wojtowicz, A. and Newton, P. M. (2015). 'When medical news comes from press releases - A case study of pancreatic cancer and processed meat'. PLOS ONE 10 (6), e0127848. https://doi.org/10.1371/journal.pone.0127848.

The Royal Australian and New Zealand College of Obstetricians and Gynaecologists (2017). ‘New research suggesting vitamin B3 can prevent miscarriage and fetal abnormality should be taken with caution'.

URL: https://ranzcog. edu . au/news/new-research-suggesting-vitamin-b3can-prevent-mis.

Vestergård, G. L. (2015). ‘Where does science news come from?’ Ph.D. thesis. Aarhus, Denmark: Aarhus University.

Victor Chang Cardiac Research Institute (2017). 'Historic discovery has the potential to prevent miscarriages and birth defects globally'. URL: https://www.victorchang. edu.au/news/pregnancy-breakthrough.

Vinkers, C. H., Tijdink, J. K. and Otte, W. M. (2015). ‘Use of positive and negative words in scientific PubMed abstracts between 1974 and 2014: retrospective analysis'. BMJ 351, h6467. https : //doi .org/10.1136/bmj . h6467.

Vogler, D. and Schäfer, M. S. (2020). 'Growing influence of university PR on science news coverage? A longitudinal automated content analysis of university media releases and newspaper coverage in Switzerland, 2003-2017'. International Journal of Communication 14, pp. 3143-3164. URL: https://ijoc.org/index.php/ijoc/article/view/13498.

Walker, M. (2021). 'U.S. newsroom employment has fallen $26 \%$ since 2008 '. Pew Research Center. URL: https://www . pewresearch . org/fact-tank/2020/04/20/u -s-newsroom-employment-has-dropped-by-a-quarter-since-2008/.

Watermeyer, R. and Lewis, J. (2018). 'Institutionalizing public engagement through research in UK universities: perceptions, predictions and paradoxes concerning the state of the art'. Studies in Higher Education 43 (9), pp. 1612-1624. https://doi.org/10.1080/03075079.2016.1272566. 
Watkins, E. (2019). 'What we lose with the decline of mainstream science journalists'. Crikey. URL: https://www.crikey.com.au/2019/01/24/science-jo urnalism-denialism/.

Weitkamp, E. and Eidsvaag, T. (2014). 'Agenda building in media coverage of food research'. Journalism Practice 8 (6), pp. 871-886. https://doi.org/10.1080/17512786.2013.865966.

Yavchitz, A., Boutron, I., Bafeta, A., Marroun, I., Charles, P., Mantz, J. and Ravaud, P. (2012). 'Misrepresentation of randomized controlled trials in press releases and news coverage: a cohort study'. PLoS Medicine 9 (9), e1001308. https://doi.org/10.1371/journal.pmed.1001308.

Young Lin, L. L. and Rosenkrantz, A. B. (2017). 'The U.S. online news coverage of mammography based on a Google News search'. Academic Radiology 24 (12), pp. 1612-1615. https://doi.org/10.1016/j.acra.2017.05.011.

Authors

\section{How to cite}

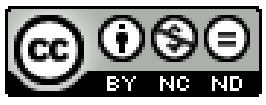

Georgia is a Ph.D. candidate and Research Assistant at the Melbourne School of Population and Global Health within the Faculty of Medicine, Dentistry and Health Sciences at the University of Melbourne. Georgia's Ph.D. is in the fields of science communication and public health. E-mail: georgia.dempster@unimelb.edu.au.

Georgina is a Senior Research Fellow at the Melbourne School of Population and Global Health within the Faculty of Medicine, Dentistry and Health Sciences at the University of Melbourne. Georgina has a background in health psychology with a major focus on social epidemiology. She has extensive experience in quantitative research across a broad range of content areas including disability, women and children's health, public health law, mental health and wellbeing, suicide prevention and violence against women.

E-mail: georgina.sutherland@unimelb.edu.au.

Louise is a Professor at the Melbourne School of Population and Global Health within the Faculty of Medicine, Dentistry and Health Sciences at the University of Melbourne. Louise is a health sociologist researching lay and expert perceptions of risk and health decision-making, particularly in relation to the use of health technology. She is an expert in qualitative research methodology and the translation of evidence to clinical practice. E-mail: 1.keogh@unimelb.edu.au.

Dempster, G., Sutherland, G. and Keogh, L. (2022). 'Scientific research in news media: a case study of misrepresentation, sensationalism and harmful recommendations'. JCOM 21 (01), A06. https:/ / doi.org/10.22323/2.21010206.

(C) The Author(s). This article is licensed under the terms of the Creative Commons Attribution - NonCommercial - NoDerivativeWorks 4.0 License. ISSN 1824-2049. Published by SISSA Medialab. jcom.sissa.it 